\title{
An algorithm for controlling of cutting speed based on soft calculations
}

\author{
Maxim Bobyr ${ }^{1, *}$, Mariya Luneva $^{1}$, and Alexsey Yakushev ${ }^{1}$ \\ ${ }^{1}$ South-West State University, Department of computer engineering, 305040 Kursk, Russian Federation
}

\begin{abstract}
The algorithm for controlling of cutting speed during machining of parts on equipment $\mathrm{CNC}$ is presented in the article. A program code has been developed for controlling of cutting speed on a three-axis milling machine CNC. The fuzzy-logical MISO system in which cutting speed depends on the rotation frequency of the cutting tool and the feed is presented.
\end{abstract}

\section{Introduction}

Machining cutting of products is a universal method of manufacturing of parts. Formation of high requirements to the final product requires an increase of the level of automation and intellectualization of production processes. If the automation of processes has now reached a high level through with use of various mechatronic complexes, then the applied intellectual systems are not sufficiently able to control complex systems $[1,2]$. In this connection, the problem of increasing the level of intellectualization of control systems for equipment $\mathrm{CNC}$ arises.

\section{Control system of a machine-tool with CNC}

The experimental model of a 3-axis milling machine $\mathrm{CNC}$ is shown in Fig.1. The machine-tool includes: microcontroller Arduino Mega 2560, a control board of motors SH Ramps v.1.4, power supply $12 \mathrm{~V}$, three drivers of stepper motor MP4988, three bipolar stepper motors, mini-drill with cutting tools.

The process of forming control signals to the actuating mechanisms of a machine-tool with $\mathrm{CNC}$ includes five steps:

Step 1. Software development in Arduino IDE for controlling the movement of a cutting tool along the axes of the machine-tool with CNC.

Step 2. Download of program code via serial COMport from PC to microcontroller Arduino Mega 2560.

Step 3. Data transfer from the microcontroller Arduino Mega 2560 to the control board of motors SH Ramps.

Step 4. Data transfer from the SH Ramps to drivers of stepper motors MP4988.

Step 5. Data transfer from the drivers of stepper motors MP4988 with the subsequent transfer of impulses to bipolar stepper motors.
After that, the transfer of rotary motion from stepper motors using the shaft to the axes supports of machinetool with CNC is carried out. The motion of supports of a machine-tool leads to the movement of the cutting tool along axes of the machine-tool.

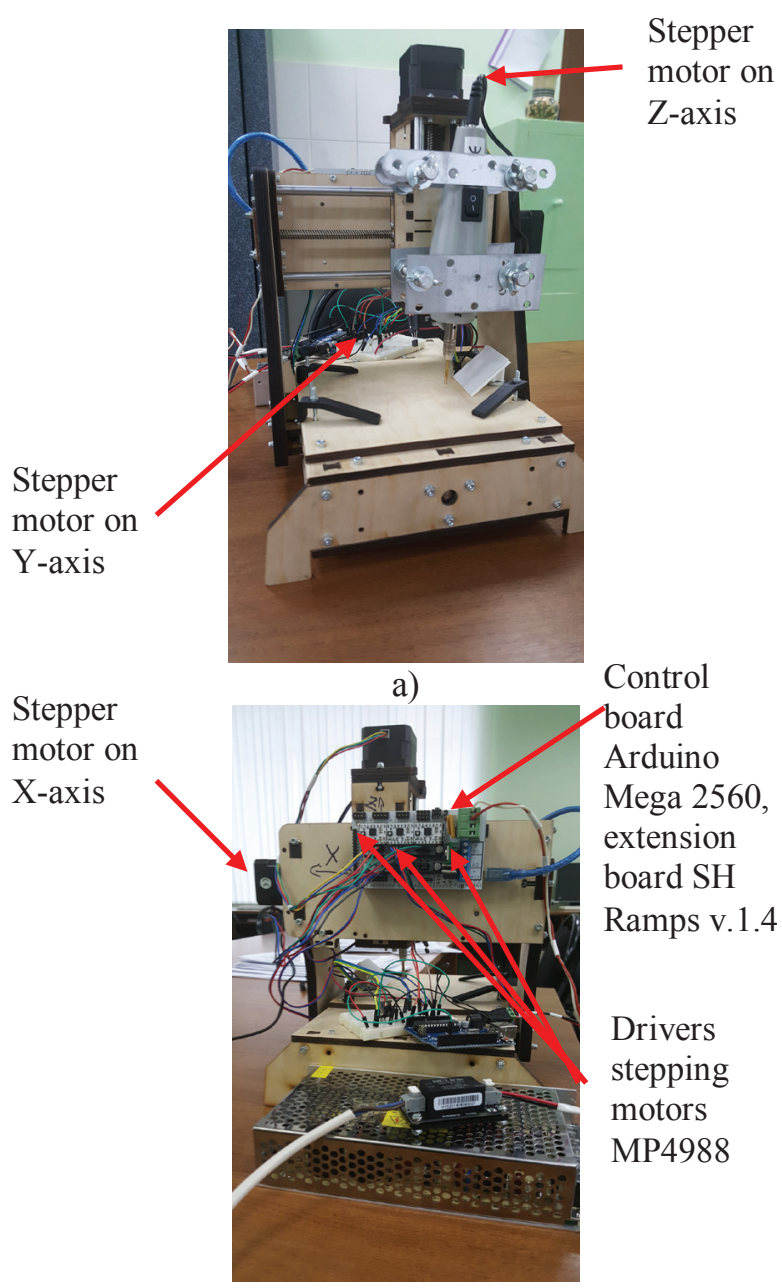

b)

Fig.1. 3-axis milling machine with CNC: (a) front view; (b) rear view

\footnotetext{
${ }^{*}$ Corresponding author: fregat_mn@rambler.ru
} 
The graphic model of the cutting process is shown in Fig.2.

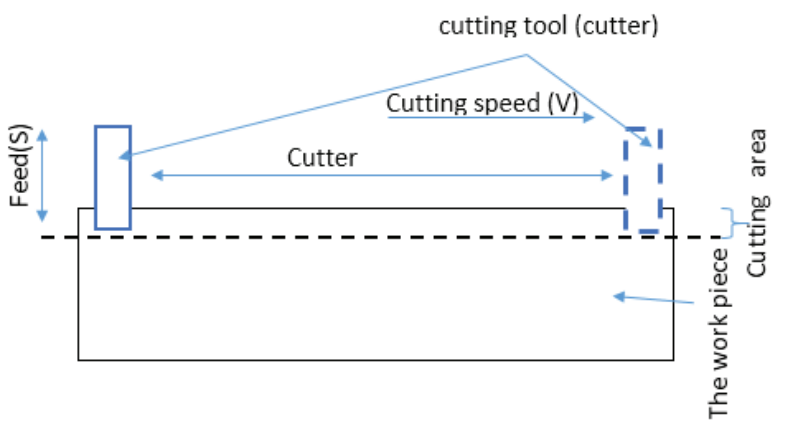

Fig.2. Process of cutting parts

\section{Hardware-software model for control of the machine-tool}

To connect MP4988 driver to the Arduino Mega microcontroller is used Table 1.

Table 1. Connecting the MP4988 driver pins to the Arduino Mega microcontroller.

\begin{tabular}{|c|c|c|}
\hline Axis name & Pin & Pin number \\
\hline \multirow{4}{*}{$X$} & DIR & 55 \\
\cline { 2 - 3 } & STR & 54 \\
\cline { 2 - 3 } & EN & 38 \\
\hline \multirow{4}{*}{$Y$} & DIR & 61 \\
\cline { 2 - 3 } & STR & 60 \\
\hline \multirow{4}{*}{$Z$} & EN & 56 \\
\cline { 2 - 3 } & DIR & 48 \\
\cline { 2 - 3 } & STR & 46 \\
\hline
\end{tabular}

Movement of the machine-tool supports is carried out along the shafts having thread of $2 \mathrm{~mm}$. That is, in order the support of the machine-tool with CNC moved $2 \mathrm{~mm}$, it is necessary to transfer $360^{\circ} / 1.8^{\circ}=200$ pulses through the STR channel.

The MP4988 driver works in several step modes: $1 / 2$, $1 / 4,1 / 8$ and $1 / 16$. Reducing the step size increases the accuracy of positioning machine-tool CNC supports. For example, in the $1 / 4$ step mode, to move the support for 2 $\mathrm{mm}$, it is necessary to transmit 800 pulses along the STR channel. The stepper motor is connected to the A1, A2, B1, B2 pins of the MP4988 driver.

To move supports along the axes of a three positioning machine-tool with $\mathrm{CNC}$, the program code stored in the microcontroller is used. The program code for moving a support along the $\mathrm{X}$-axis is shown need:

void $\operatorname{setup}()\{$

Serial.begin(9600);

pinMode (x_en, OUTPUT);

pinMode (x_step, OUTPUT);

pinMode (x_dir, OUTPUT);

digitalWrite(x_en, LOW); void x_ot_dvig(int imp, int skorost $)\{$

digitalWrite(x_dir, HIGH);

for $(\mathrm{i}=0 ; \mathrm{i}<\mathrm{imp} ; \mathrm{i}++) \quad$;

digitalWrite(x_step, HIGH);

delayMicroseconds(skorost);

digitalWrite(x_step, LOW);

delayMicroseconds(skorost); \}\}

void x k_dvig(int imp, int skorost) \{

digitalWrite(x_dir, LOW);

for $(\mathrm{i}=0 ; \mathrm{i}<\mathrm{imp} ; \mathrm{i}++) \quad$

digitalWrite(x_step, HIGH);

delayMicroseconds(skorost);

digitalWrite(x_step, LOW);

delayMicroseconds(skorost); \}\}

void flushReceive()\{ while(Serial.available())

Serial.read();

void loop() \{

char val $=$ Serial.read () ;

if $\left(\mathrm{val}=={ }^{\prime} 1\right.$ ' $)\{$

x_ot_dvig $(2000,500)$;

if $(\mathrm{val}==$ '2') \{

x_k_dvig(2000, 500); \} \}

When using the program code, it was noticed that when changing the control parameters and then loading them into the Arduino Mega microcontroller, the program code written earlier in the Arduino Mega microcontroller is executed before using this code. As a consequence, the cutting tool does not move along the specified trajectory. To solve this problem, the program code need:

\#define $\mathrm{x}$ _dir 55

\#define $x$ step 54

\#define $x \_$en 38

int $\mathrm{i}$;

void $\operatorname{setup}()\{$

pinMode ( $\mathrm{x}$ en, OUTPUT);

pinMode (x_step, OUTPUT);

pinMode (x_dir, OUTPUT);

digitalWrite(x_en, LOW);

void loop() \{

digitalWrite(x_dir, LOW);

for $(\mathrm{i}=0 ; \mathrm{i}<\overline{4000} ; \mathrm{i}++)$

digitalWrite(x_step, HIGH);

delayMicroseconds(500);

digitalWrite(x_step, LOW);

delayMicroseconds(500); $\}$

delay(2000);

digitalWrite(x_dir, HIGH);

for $(\mathrm{i}=0 ; \mathrm{i}<\overline{4000} ; \mathrm{i}++)\{$

digitalWrite(x_step, HIGH);

delayMicroseconds(500);

digitalWrite(x_step, LOW);

delayMicroseconds(500);

delay(2000); $\}$

- to have separate functions for implementing movement of supports along each of axis;

- to use the function Serial.Available().This function allows to stop the execution of the program code until 
the operator gives the start command from the computer keyboard.

\section{Fuzzy MISO-system control of cutting speed}

During the experiments it was found that depending on the change in the number of pulses (i), the amount of displacement of the supports along each axis changes. The time delay between transmission of pulses ( $t$ ) affects the speed of passage of the cutting tool along the axis (v). Also, the speed of passage of the cutting tool along the axis depends from frequency of rotation of the spindle drill (n). The fuzzy MISO-system for control of cutting speed was created on the basis of this data $[3,4]$ (Fig. 3).

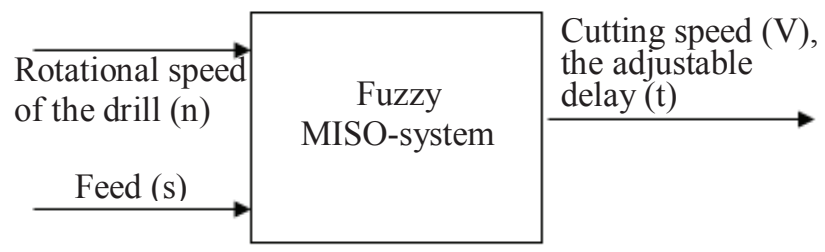

Fig.3. Fuzzy MISO-system control of cutting speed

The fuzzy system has two input variables:

$$
\begin{gathered}
n=\left\{n_{1}\right\}+\left\{n_{2}\right\}+\left\{n_{3}\right\}, \\
s=\left\{s_{1}\right\}+\left\{s_{2}\right\}+\left\{s_{3}\right\},
\end{gathered}
$$

and one output variable:

$$
t=\left\{t_{1}\right\}+\left\{t_{2}\right\}+\left\{t_{3}\right\}+\left\{t_{4}\right\}+\left\{t_{5}\right\},
$$

where $\mathrm{n}_{1}, \ldots, \mathrm{n}_{3}$ are terms of the input variable of fuzzy set $n ; s_{1}, \ldots, s_{3}$ are terms of the input variable of fuzzy set $s ; t_{1}, \ldots, t_{5}-$ terms of the output variable of fuzzy set $t[5$, $6]$.

Input and output variables are described by triangular membership functions (MF), the graphs of which are shown in Fig. 4, where $\mu(\mathrm{n}), \mu(\mathrm{s})$ and $\mu(\mathrm{t})$ are membership functions of the fuzzy sets $\mathrm{n}, \mathrm{s}$ and $\mathrm{t}$, respectively. $[7,8]$.

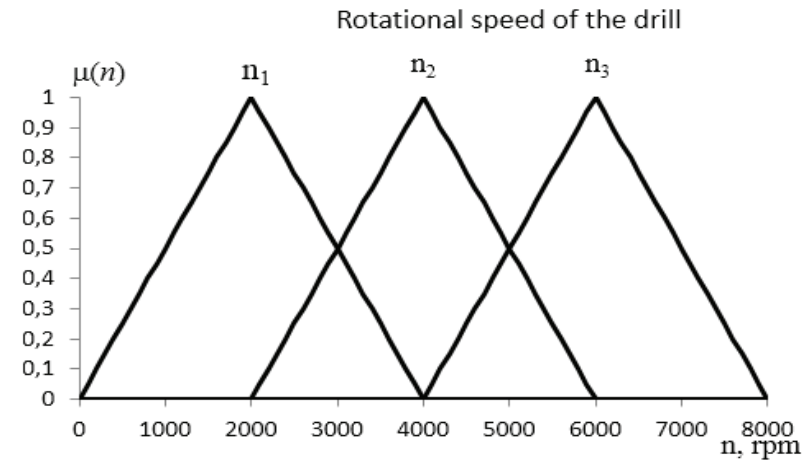

a)

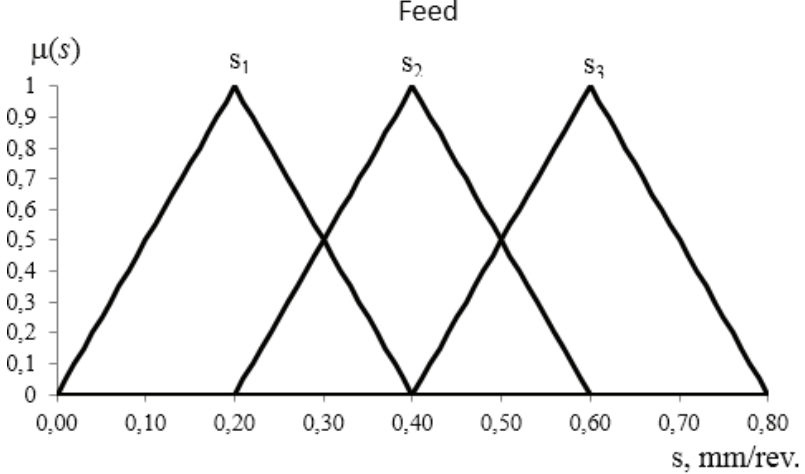

b)

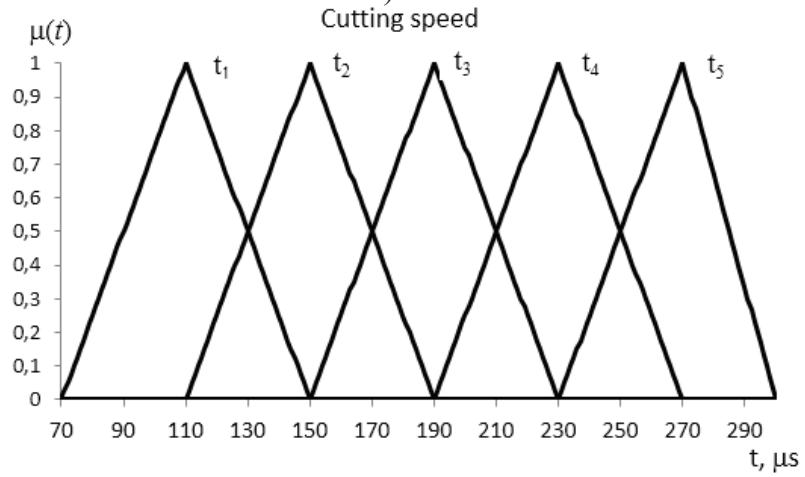

c)

Fig.4. Graphics of triangular membership functions: $(a, b)$ are input variables $\mathrm{n}$ and $\mathrm{s}$, respectively; (c) is output variable t.

The MF is given by the following formula:

$$
f(x ; a, b, c)= \begin{cases}0, & x \leq a ; \\ \frac{x-a}{b-a}, & a \leq x \leq b ; \\ \frac{c-x}{c-b}, & b \leq x \leq c ; \\ 0, & c \leq x .\end{cases}
$$

The graphical view of the membership function is shown in Fig.5.

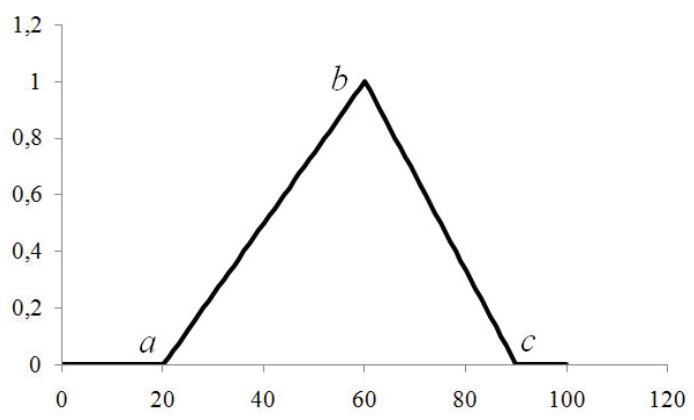

Fig.5. The membership function of triangular shape.

For fuzzification of the input variables were used the following data: the frequency of rotation of the drill spindle is $0 \div 8000 \mathrm{rpm}$. Feed of cutting tool is $0 \div 0.8$ $\mathrm{mm} / \mathrm{rev}$. The delay time is limit of $70 \div 300 \mu \mathrm{s}$. If the time delay is less than $70 \mu \mathrm{s}$, the bipolar stepper motors do not rotate. The fuzzy knowledge base is given by nine fuzzy rules and is presented in Table 2 [9]. 
Table 2. Fuzzy knowledge base.

\begin{tabular}{|c|c|c|c|c|c|c|c|c|c|c|c|}
\hline FR & \multicolumn{2}{|c|}{ If } & That & FR & \multicolumn{2}{|c|}{ If } & That & FR & \multicolumn{2}{|c|}{ If } & That \\
\hline $\mathrm{FR}_{1}$ & \multirow{3}{*}{$\mathrm{n}_{1}$} & $\mathrm{~S}_{1}$ & $\mathrm{~V}_{5}$ & $\mathrm{FR}_{4}$ & \multirow{3}{*}{$\mathrm{n}_{2}$} & $\mathrm{~S} 1$ & $\mathrm{~V}_{4}$ & $\mathrm{FR}_{7}$ & \multirow{3}{*}{$\mathrm{n}_{3}$} & $\mathrm{~S} 1$ & $\mathrm{~V}_{3}$ \\
\hline $\mathrm{FR}_{2}$ & & $\mathrm{~S}_{2}$ & $\mathrm{~V}_{4}$ & $\mathrm{FR}_{5}$ & & $\mathrm{~S}_{2}$ & $\mathrm{~V}_{3}$ & $\mathrm{FR}_{8}$ & & $\mathrm{~s}_{2}$ & $V_{2}$ \\
\hline $\mathrm{FR}_{3}$ & & $\mathrm{~S}_{3}$ & $V_{3}$ & $\mathrm{FR}_{6}$ & & $\mathrm{~S}_{3}$ & $V_{2}$ & $\mathrm{FR}_{9}$ & & $\mathrm{~S}_{3}$ & $\mathrm{~V}_{1}$ \\
\hline
\end{tabular}

The defuzzification was carried out on the base of the method center of gravity $[8,9,10]$

$$
V=\frac{\int_{\min }^{\max } v \mu^{\prime}(t) d t}{\int_{\min }^{\max } \mu^{\prime}(t) d t}
$$

where min, max - limits of integration of fuzzy set; $\mu^{\prime}(t)$ - degree of membership function truncated terms of output variable.

The structure of fuzzy inference with usage of soft arithmetic operations is presented in articles [11, 12 13]. The structure of algorithm for control of cutting speed is shown in Fig. 6.

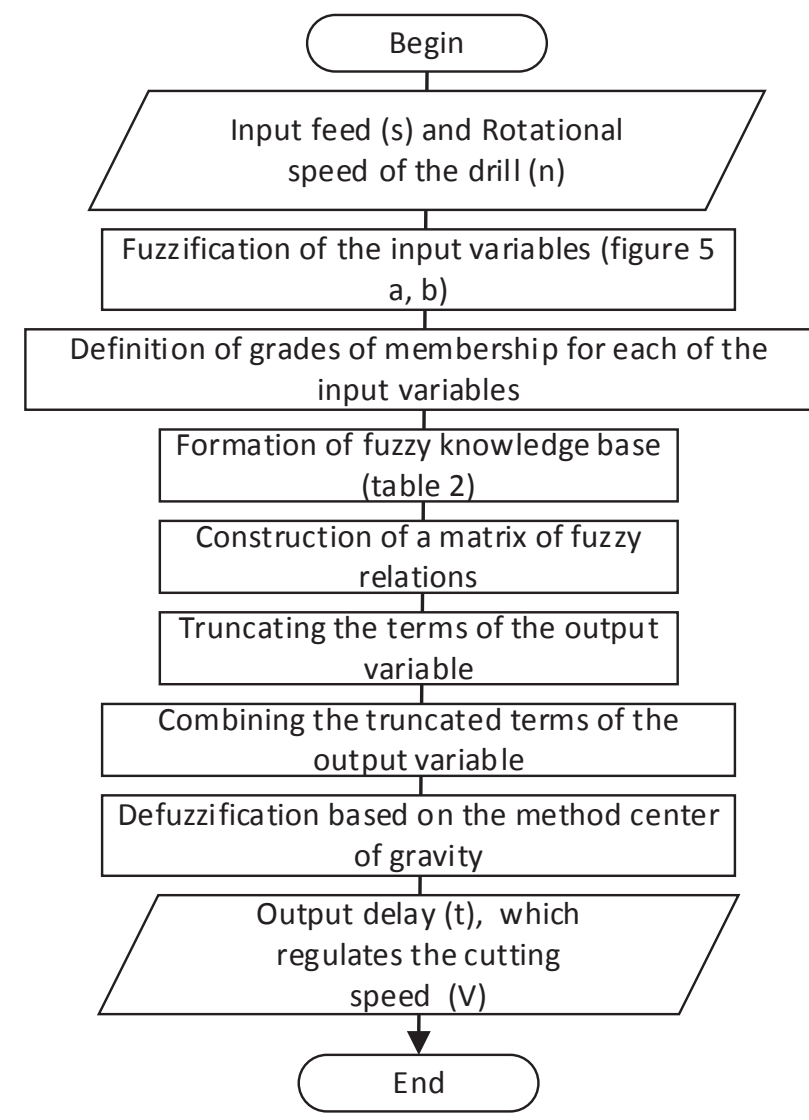

Fig.6. Fuzzy inference algorithm based on soft arithmetic operations

The resultant surfaces received during modeling of fuzzy inference with usage of soft and hard arithmetic operations are shown in Fig. 7.

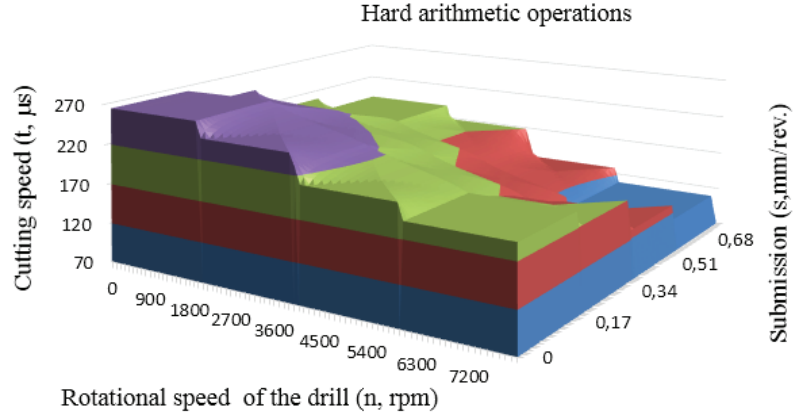

a)

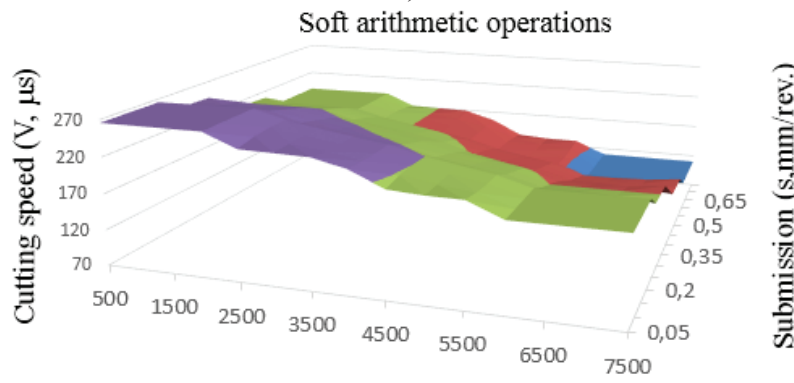

Rotational speed of the drill ( $\mathrm{n}, \mathrm{rpm})$

b)

Fig.7. Fuzzy MISO-system with: (a) hard arithmetic operations; (b) soft arithmetic operations

Analysis of the graphs presented in Fig. 7 showed that during using in fuzzy inference of soft arithmetic operations and control of the cutting speed is performed more smoothly than with using of hard operations. Therefore, using soft arithmetic operations in fuzzy inference improves quality of the processed details. At the same time, the developed fuzzy MISO-system allows to extend the life of the cutting tools, since during the cutting, there is no overheating of the parts.

\section{Conclusion}

In this work the program code for controlling process of cutting on a three-axis milling machine with $\mathrm{CNC}$ is presented. The problem of deleting previous commands from the memory of the microcontroller, when loading the next command, was solved. Fuzzy MISO-system for controlling cutting speed, which depends on the rotation frequency of the spindle drill and the feed, is presented in the article. On the basis of the analysis of the resulting surfaces, it was concluded that, when using soft arithmetic operations, the accuracy in the machining of parts improves.

This work was supported by the grant of the President of the Russian Federation MD-707.2017.8 and the Goszadaniya: Agreement No. 2.3440.2017 / PCH.

\section{References}

1. Hui Liu, En Ming Miao, Xin Yuan Wci, Xin Dong Zhuang, International journal of machine tools and manufacture 113, 35 (2016). DOI: 10.1016/j.ijmachtools.2016.11.001 
2. Mehmet Emin Aktan, Nihat Akkus, Abdurrahman Yilmaz, Erhan Akdogan, MATEC Web of Conferences 45, 05002 (2016). DOI: $0.1051 /$ matecconf $/ 20164505002$

3. K. Yongjin, G.W. Fischer, T. Tzu-Liang, Journal of manufacturing systems 21, 440 (2002). DOI: $10.1016 / \mathrm{s} 0278-6125(02) 80050-4$

4. Earl-Juei Wang, Tai-Sheng Su, Ming-Hsien Chang, Journal of manufacturing systems 32, 206(2013). DOI: $10.1016 /$ j.jmsy.2012.10.003

5. A. Pegat, Nechetkoe modelirovanie i upravlenie 2013.

6. A. Gupta, H.Singh, A. Aggarwal, Expert Systems with Applications 38, 6822(2011). DOI: 10.1016/j.eswa.2010.12.057

7. M.V. Bobyr, V.S. Titov, A.A. Nasser, Journal of Machinery Manufacture and Reliability 44, 633 (2015). DOI: $10.3103 / \mathrm{s} 1052618815070067$

8. M.V. Bobyr, N.A. Milostnaya, S.A. Kulabuhov, Applied Soft Computing, (2017), (In Press) DOI: 10.1016/j.asoc.2017.05.040

9. M.V. Bobyr, S.A. Kulabuhov, N.A. Milostnaya, 2nd International Conference on Industrial Engineering, Applications and Manufacturing (ICIEAM), (2017), DOI: 10.1109/icieam.2016.7910970

10. M.V. Bobyr, A.S. Yakushev, N.A. Milostnaya, 2nd International Conference on Industrial Engineering, Applications and Manufacturing (ICIEAM), (2017), DOI: 10.1109/ICIEAM.2016.7910971

11. M. Liang, T. Yeap, A. Hermansyah, S. Rahmati, International Journal of Machine Tools and Manufacture 43, 1497(2003). DOI: 10.1016/S08906955(03)00166-4

12. M.Bobyr, V.Titov, A.Belyaev, MATEC Web of Conferences 79, 01052(2016). DOI: https://doi.org/

13. I.V. Chernova, S.A. Sumin, M.V. Bobyr, S.P. Seregin, Biomedical Engineering 49, 263 (2016). DOI: https://doi.org/10.007/s10527-016-9545-y 